\title{
FEMORAL HERNIA - AN UNUSUAL PRESENTATION WITH ENTEROCUTANEOUS FISTULA WITH ILEAL MUCOSAL PROLAPSE
}

Navneet Parashar, Tej Pratap Singh, Rakesh Kumar Sharma,

1. Assistant Professor. Department of General Surgery, Govt. Medical College, Kota.

2. Resident Doctor. Department of General Surgery, Govt. Medical College, Kota.

3. Professor \& Unit Head. Department of General Surgery, Govt. Medical College, Kota.

\section{CORRESPONDING AUTHOR:}

Dr. Navneet Parashar, KR 227/3 MBS Hospital Campus, Nayapura, Kota, Rajasthan.

E-mail: drtps05@hotmail.com

ABSTRACT:_Femoral Hernia is less common form of groin hernia. It is more common in females due to wide femoral canal and weak pelvic musculature $(1,2)$. It generally present with groin swelling and features of intestinal obstruction. We are reporting an unusual presentation of femoral hernia in 80 year old female with enterocutaneous fistula with gut mucosal prolapse like a pathological mucosal prolapse of ileostomy. We performed urgent exploratory laprotomy for intenstional obstruction with gut mucosal prolapse from the fistulous site with favorable outcome.

KEY WORDS: Femoral Hernia, enterocutaneous fistula, mucosal prolapse.

CASE REPORT: Mangi Bai 80 yr. old female admitted in emergency ward of M.B.S. Hospital Kota (Rajasthan) with chief complains of prolapse of a tubular structure through the right groin wound for 4-6 hours. It was progressively increasing in size and was associated with abdominal distension.

On Examination there was about 25 to $30 \mathrm{~cm}$ gut mucosal prolapse through an excoriated wound present in right groin below and lateral to pubic tubercle. Abdomen was distended, non tender without guarding and rigidity.

There was past history of hospitalization one year back for intestinal obstruction. After conservative management of 4 to 5 days, she was referred to higher centre for further management.

She admitted in another hospital where she was diagnosed intestinal obstruction (? ileus) and managed conservatively. After 3 to 4 weeks patient developed a wound on right groin with faecal discharge. The amount was $200-250 \mathrm{ml} /$ day. She took multiple consultations and was treated conservatively with antibiotics, anti inflammatory, PPIs, dressings and high protein diet at home for last 10-12 months.

After initial resuscitation patient was explored by using lower midline incision under G.A. Peritoneal cavity was opened whole of the gut was explored. A loop of ileum around one feet proximal to ileocecal junction was herniating through femoral canal. Defect was widened, adhesions were removed and gut was reduced back in peritoneal cavity. Pregangrenous segment of ileum containing fistulous opening was resected and end to end ileoileal anastomosis was done in two layers. Hernial defect was repaired. External wound was closed after thorough cleaning with hydrogen peroxide, saline and povidone iodine. There was no faecal contamination in peritoneal cavity and rest of the gut except herniated segment was 
absolutely normal. Abdominal wound closed in layers after drain placement in right iliac fossa. On $5^{\text {th }}$ post operative day drain removed and patient discharged from the hospital on $8^{\text {th }}$ postoperative day.

DISCUSSION: Femoral hernia may rarely present as enterocutaneous fistula if neglected (3). This patient developed features of intestinal obstruction one year back possibly due to right side femoral hernia. Patient was managed conservatively and relieved temporarily. Because of ischemic necrosis of part of circumference of strangulated ileum in femoral canal, faecal matter collected beneath skin which eroded the skin and converted into enterocutaneous fistula.

As the part of circumference of ileum was involved, the continuity of whole gut was maintained so patient did not develop intestinal obstruction.

Due to small hernial defect and adhesions, faecal contamination of peritoneal cavity did not occur and loop of ileum did not prolapsed. Thus constant peristaltic movement of intestine lead to prolapse of ileal mucosa, similar to pathological mucosal prolapse of a loop ileostomy. This led to break in continuity of the gut and patient developed acute intestinal obstruction. When patient developed ileal mucosal prolapse with intestinal obstruction, she became aware about the seriousness of problem which compelled her to seek emergency surgical advice.

SUMMARY \& CONCLUSION: Femoral hernia though a rare form of groin hernia but it is not very uncommon in females.

Usual presentation of femoral hernia is in form of groin swelling and acute intestinal obstruction but if neglected it may rarely present in form of enterocutaneous fistula with intestinal mucosal prolapse through fistulous opening in groin.

\section{REFERENCES:}

1. Perlman JA, Hoover HC, Safer PK. Femoral hernia with strangulated Meckel diverticulum (Littre's hernia): case report and review of the literature. Am J Surg 1980; 139:286-289.

2. U. Dahlstrand, S. Wollert, P. Nordin, G. Sandblom, and U. Gunnarsson, "Emergency femoral hernia repair: a study based on a national register," Annals of Surgery, vol. 249, no. 4, pp. 672-676, 2009.

3. Lamrani J, El Bouhaddouti H, Ankouz A, F-Z Z, Louchi A : Enterocutaneous fistula caused by strangulated groin hernia : five cases in Morocco. Med Trop (Mars). 2011 Apr;71(2):183-4. PMID: 21695881 [PubMed - indexed for MEDLINE] 


\section{CASE REPORT}

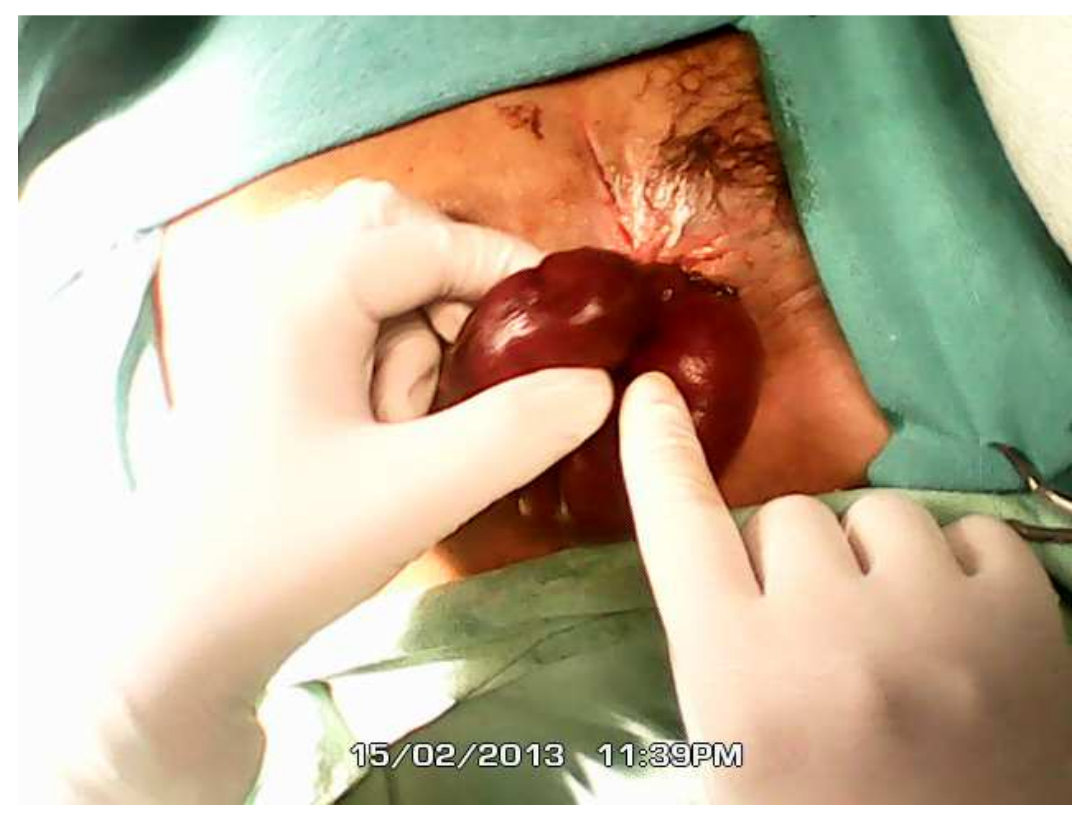

Figure 1. Prolapsed small intestine mucosa from right groin , lateral and below to right pubic tubercle.

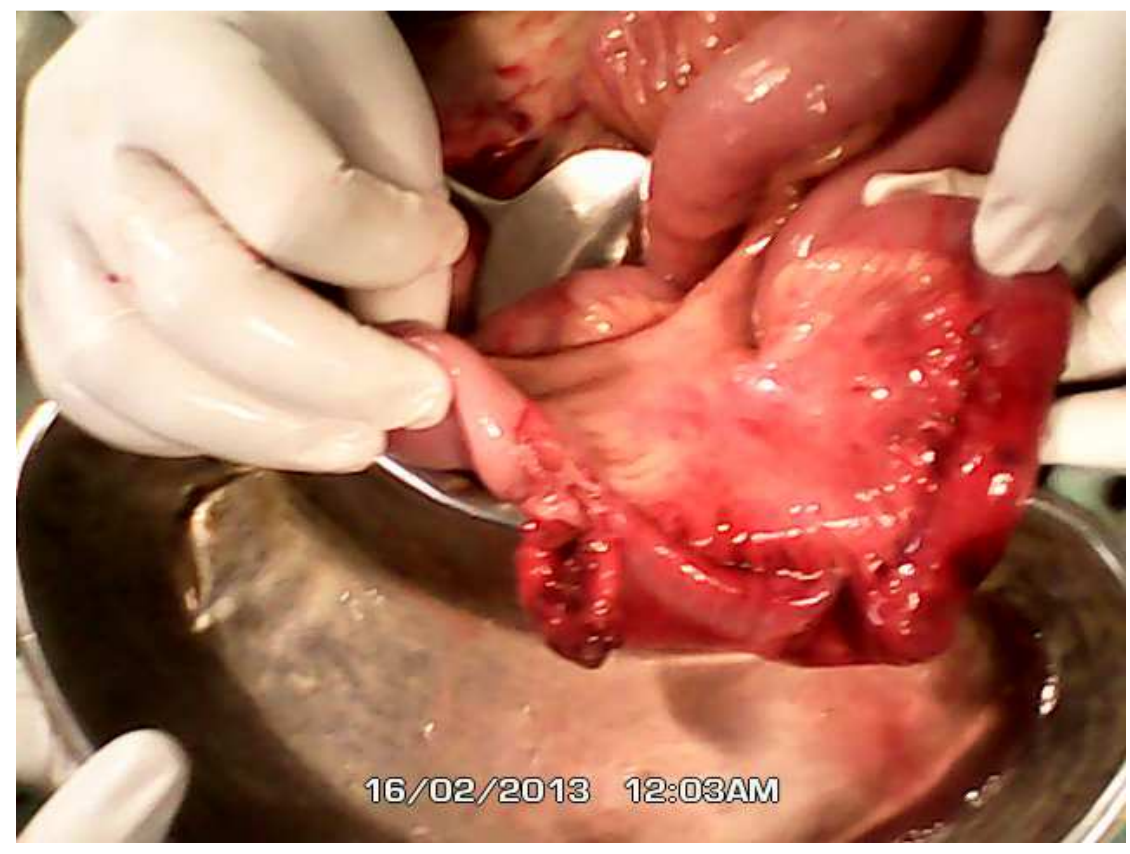

Figure 2. mucosal prolapse from ileum. 


\section{CASE REPORT}

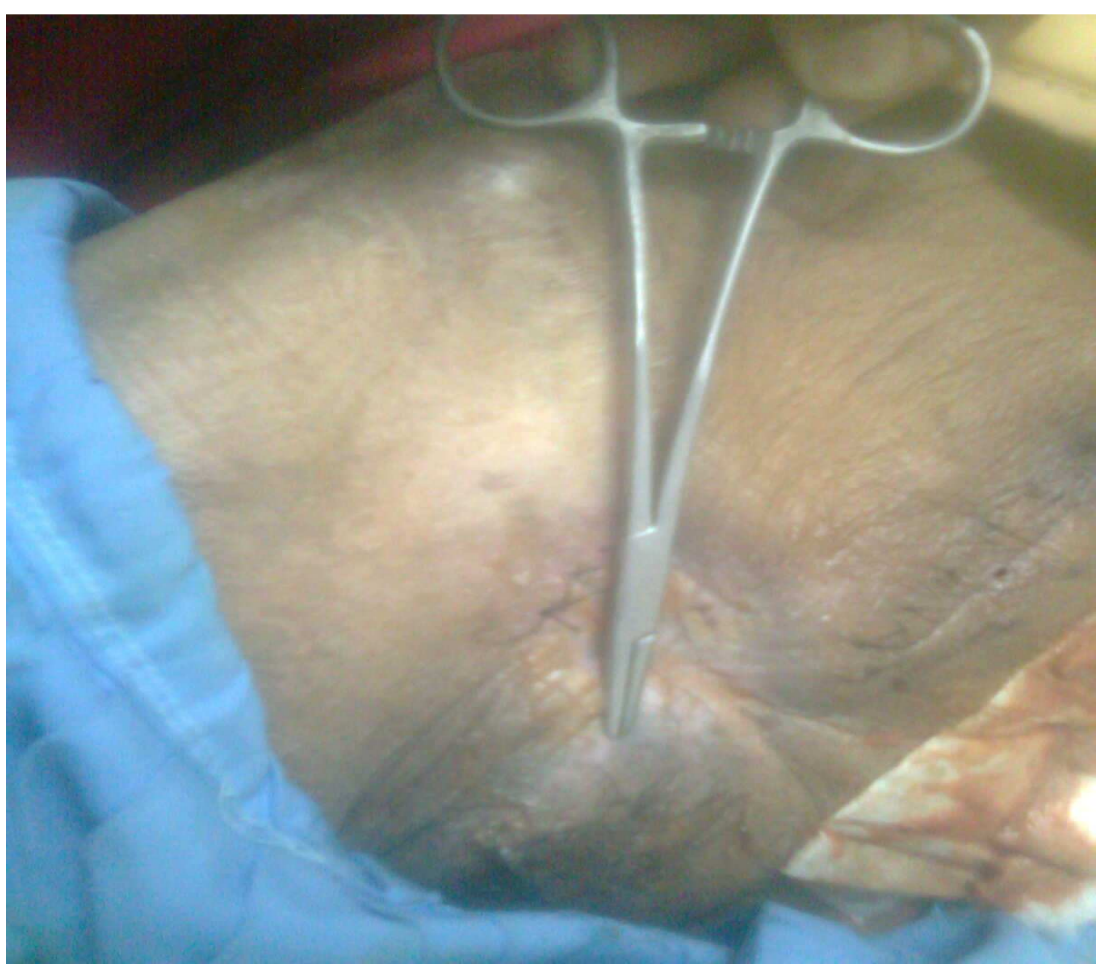

Figure 3. Sutured postoperative wound lateral and below to right pubic tubercle. 